\title{
Expression of inhibitor of apoptosis protein BIRC7/livin in adrenocortical tumors.
}

Endocrine and Diabetes Unit, Department of Internal Medicine I, University Hospital of Wuerzburg, Germany ${ }^{2}$ Endocrinology and Metabolic Disease, Catholic University, Rome, Italy.

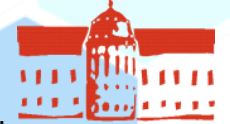

P535

INTRODUCTION: Adrenocortical tumors (ACT) consist of frequent benign adenomas (ACA) and rare highly malignant carcinomas (ACC). BIRC7/livin, a member of the inhibitors of apoptosis family, plays an important role in cancer development and progression in a variety of human malignancies. BIRC7 encodes two splicing variants, livin $\alpha$ and livin $\beta$, which present antiapoptotic property to different stimuli. Apoptosis initiated by etoposide, one of the first line chemotherapeutical drug used for ACC, is blocked only by the $\beta$ isoform. Patients with livin $\beta$ overexpression could be resistent to treatment with etoposide.

The aim of our study was to evaluate the expression of BIRC7 in normal adrenal glands and adrenocortical tumors.

METHODS: BIRC7 mRNA expression was detected by quantitative real-time reverse transcription PCR (qRT-PCR) analysis in fresh-frozen tissue samples (27 ACC, 23 ACA, and 20 normal adrenal glands, NA) (Tab.1). The mean value of the threshold cycle of each sample was normalized with $\beta$-actin ( $\Delta \mathrm{Ct}$ value). Among these, 15 were paired samples of tumor and corresponding normal adrenal tissue (12 ACA and 3 ACC). To evaluate the different expression of the two isoforms of BIRC7 in ACT and NA, we used specific primer to amplify 216-bp livina and 162-bp livin $\beta$ in all of 15 paired samples. Livin isoforms were then identified by $4 x$ agarose gel.

The correlation between BIRC7 levels and clinical and pathological parameters was also investigated.

RESULT: BIRC7 mRNA levels were similar between NA and ACA, but significantly increased in ACC ( $P<0.005$ vs both ACA and NA) (Fig.1). $B I R C 7$ was more expressed in tumor than corresponding normal tissue in 12 out 15 paired samples (Fig. 2). No significant difference was found between cortisol- and non cortisol-secreting tumors.

\begin{tabular}{|c|c|c|}
\hline & ACC & ACA \\
\hline $\mathrm{N}^{\circ}$ patients & 27 & 23 \\
\hline Gender F:M & 13:14 & 15:8 \\
\hline Age (years) mean $\pm S D$ & $51,8 \pm 14,4$ & $47,3 \pm 12,0$ \\
\hline Tumor size $(\mathrm{cm})$ meantSD & $10,2 \pm 5,6$ & $3,2 \pm 2,5^{\star}$ \\
\hline $\begin{array}{l}\text { Secreting (\%): } \\
\text { - cortisol } \\
\text { - non-cortisol }\end{array}$ & $\begin{array}{l}12(44,4 \%) \\
15(55,6 \%)\end{array}$ & $\begin{array}{l}11(47,8 \%) \\
12(52,2 \%)\end{array}$ \\
\hline $\begin{array}{l}\text { ENSAT Tumor Stage } \\
\text { - III } \\
\cdot \text { III }\end{array}$ & $\begin{array}{l}13(50 \%) \\
9(34,6 \%) \\
4(15,4 \%)\end{array}$ & Not appl. \\
\hline Ki67\% meantSD & $17,5 \pm 10,6$ & Not appl. \\
\hline Weiss score mean \pm SD & $6,2 \pm 2,0$ & Not appl. \\
\hline
\end{tabular}

Tab. 1: Clinical characteristics of patients in ACC ano ACA group. Not appl.: data not applicable. ${ }^{*} P<0.05$
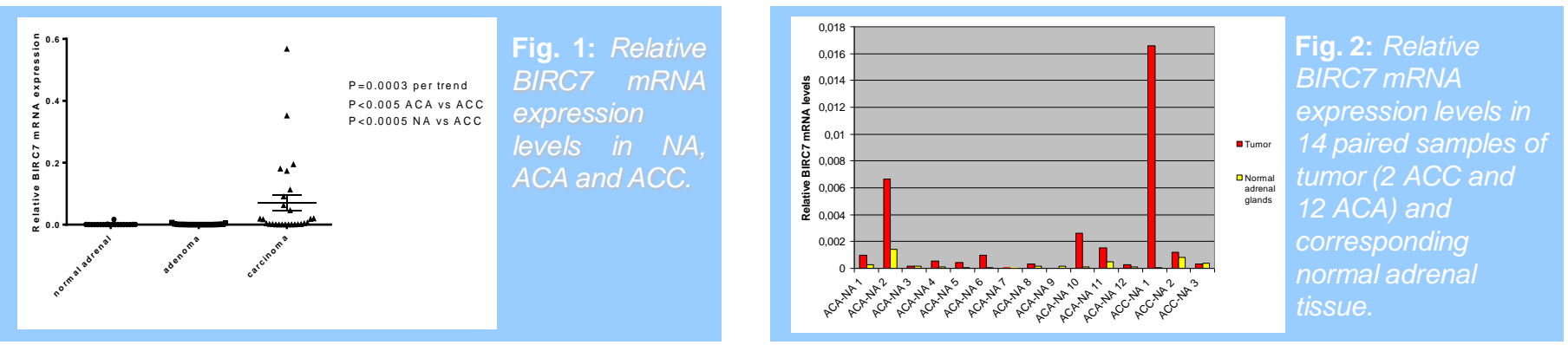

In the ACC group, we did not observe any significant correlation between BIRC7 levels and clinical parameters, such as age, tumor size, Weiss score, ENSAT tumor stage, Ki67 index and number of metastasis at diagnosis. No significant differences were observed in terms of overall survival (OS) and time to progression/disease free survival (TTP/DFS) (Fig.3).

Both livin isoforms $\alpha$ and $\beta$ were detected in all 15 paired samples (Fig.4), being livin $\beta$ more expressed than $\alpha$. The band of livin $\beta$ was particularly strong in ACC in respect to ACA and NA. Both isoforms were higher in tumors then in NA..
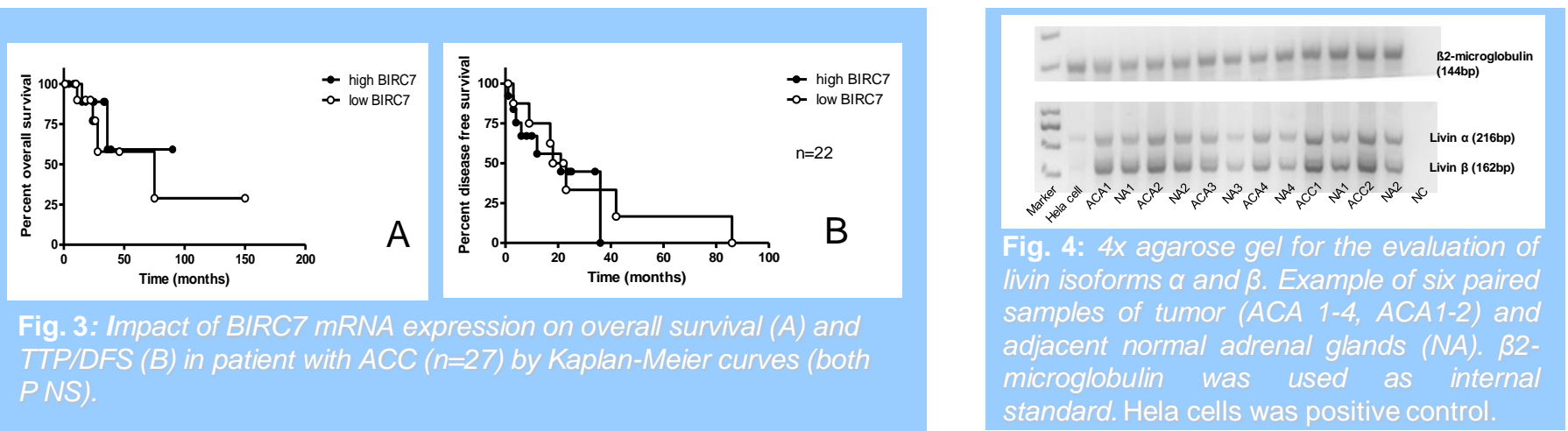

CONCLUSION: To our knowledge, this is the first study that investigates the expression of BIRC7/livin in normal adrenal and adrenocortical tumors. We demonstrate that BIRC7 is specifically over-expressed in ACC. As previously reported for different human cancers, these findings open a new perspective for the use of livin as a potential therapeutic target in ACC. 